\title{
Studies on blends of cycloaliphatic epoxy resin with varying concentrations of carboxyl terminated butadiene acrylonitrile copolymer I: Thermal and morphological properties
}

\author{
GARIMA TRIPATHI* and DEEPAK SRIVASTAVA \\ Department of Plastic Technology, H.B. Technological Institute, Kanpur 208 002, India
}

MS received 1 August 2008; revised 20 August 2008

\begin{abstract}
Differential scanning calorimetric (DSC), thermogravimetric analysis (TGA) and dynamic mechanical analysis (DMA) of the blends of cycloaliphatic epoxy (CAE) resin toughened with liquid elastomer such as carboxyl terminated butadiene acrylonitrile copolymer (CTBN) have been carried out. Exothermal heat of reaction due to cross linking of the resin in the presence of diamino diphenyl sulphone (DDS, an amine hardener) showed a decreasing trend with increasing rubber concentration. Enhancement of thermal stability as well as lower mass loss of the epoxy-rubber blends with increasing rubber concentration have been observed in thermogravimetric analysis (TGA). Dynamic mechanical properties reflected a monotonic decrease in the storage modulus $\left(E^{\prime}\right)$ with increasing rubber concentration. The loss modulus $\left(E^{\prime \prime}\right)$ and the loss $\operatorname{tangent}(\tan \delta)$ values, however, showed an increasing trend with rise of temperature up to a maximum (peak) followed by a gradual fall in both cases.
\end{abstract}

Keywords. Cycloaliphatic epoxy resin; carboxyl terminated butadiene acrylonitrile; differential scanning calorimetry; thermogravimetric analysis; dynamic mechanical analysis.

\section{Introduction}

Cycloaliphatic epoxy (CAE) resins have good heat and chemical resistance, superior mechanical and electrical properties and excellent processability (Batzer 1964; Lee 1988). Because of their low viscosity and other properties reliability, cycloaliphatic epoxy resins have been extensively used in a wide variety of industrial applications, such as coatings, adhesives, reactive diluents and encapsulates of electronic components and printed circuit boards (Lee and Neville 1982). However, their mechanical elongation and toughness are poor because of their compact molecular structure and their high cross linking density, which arises from the homopolymerization mechanism generally used in the curing process (Tokixava et al 1993; Soucek 2003). In recent years, epoxy resins, particularly cycloaliphatic ones, have been shown to have other drawbacks: they are intractable after curing (i.e. they last too long in the environment) (Buchwalter and Kosbar 1996), and they shrink upon curing (Sadhir and Luk 1992).

To overcome these drawbacks, i.e. to get rid of their brittleness and to increase the performance of these materials, it is proposed to blend cycloaliphatic epoxy resin with carboxyl terminated butadiene acrylonitrile copolymer (CTBN). In the previous years, studies on the modifica-

\footnotetext{
*Author for correspondence (tgarima@iitk.ac.in)
}

tion of diglycidyl ether of bisphenol-A based (DGEBA) epoxies with various reactive liquid rubbers were found abundantly in the literature (Visconti and Marchessault 1974; Riew et al 1976, 1984; Bartlet et al 1985; Pearson and Yee 1986; Chen and Tan 1991; Verchere et al 1991a; Kim and Robertson 1992; Chen et al 1993; Frigione et al 1995). The use of such rubber-toughened epoxy resins have wide use as structural and local bearing materials, in adhesives, encapsulants for electrical and electronic components. In these applications, thermal stability and structural integrity of the materials at elevated temperatures are of primary importance especially when the product undergoes long-term serviceability in dynamic conditions. Conventional methods, viz. Fourier transform infrared (FTIR) spectroscopy, physico-mechanical properties, failure mechanism through scanning electron microscopy (SEM) and wide angle X-ray scattering (WAXS) for varied rubber-epoxy systems have been reported earlier (Sultan et al 1971; Sultan and Mc-Garry 1973; Pearson and Yee 1989; Yee and Pearson 1989; Nigam et al 1998), but similar investigations on CAE needs a lot of attention to use as toughened matrices. However, there existed some reports on the modification of CAE by CTBN and silicone elastomers in literature (Soldates and Burhans 1971; Bittmann and Ehrenstein 1998). Therefore, in the present investigation, it is proposed to study the thermal, dynamic mechanical and morphological analysis of such blend systems. 


\section{Experimental}

\subsection{Materials}

Cycloaliphatic di-epoxy used were 3,4-epoxycyclohexylmethyl, 3', 4'-epoxycyclohexane carboxylate (CY 230) (epoxide equivalent weight: $145 \mathrm{eq} / \mathrm{g}$ ) and agent 4,4'diamino diphenyl sulphone (DDS) (HT 976) which were procured from M/s Ciba Speciality Chemicals Pvt. Ltd., Mumbai, India. The elastomer employed was carboxyl terminated butadiene acrylonitrile (CTBN) copolymer (viscosity: $625,000 \mathrm{mPas}$ at $27^{\circ} \mathrm{C}$ ) (Trade name: Hycar $1300 X 13$ ) and was kindly supplied by M/s Emerald Performance Materials, LLC, Hong Kong, with molecular weight $\overline{M n}$ of 3500 , containing $27 \%$ acrylonitrile content and $32 \%$ carboxyl content.

\subsection{Preparation of samples}

Four blend samples containing $0-15 \mathrm{phr}$ of CTBN were prepared according to the procedure adopted in our previous work (Tripathi and Srivastava 2007). The calculated quantity of $\mathrm{CAE}$ resin (as per the formulation given in table 1) was, firstly, stirred at $120^{\circ} \mathrm{C}$ for $1 \mathrm{~h}$ to entrap all the air bubbles from the resin. To this homogeneous resin, the calculated quantity of DDS was added and stirred at $130 \pm 5^{\circ} \mathrm{C}$ for $30 \mathrm{~min}$ to get a clear mixture. The mixture was then poured into preheated open iron mold $\left(8^{\prime \prime} \times 8^{\prime \prime}\right)$ and cured into hot air oven at $170^{\circ} \mathrm{C}$ for $1 \mathrm{~h}$ and then post cured at $200^{\circ} \mathrm{C}$ for $2 \mathrm{~h}$ for complete crosslinking. All the tests were performed by cutting the sample from the cured sheet.

\subsection{Characterization of samples}

2.3a Differential scanning calorimetric (DSC) analysis: Cure temperature of the prepared samples were observed by taking very little quantity of blend samples into shallow aluminium pan of DSC (TA Instrument, USA; Model DSC 2920), which was sealed by an aluminium cover. This was placed in sample cell of the instrument. The starting temperature, programmed rate and final temperature were taken at a heating rate of $10^{\circ} \mathrm{C} / \mathrm{min}$. Dynamic scans were obtained which were used for assuming the cure temperature.

Table 1. Composition of cycloaliphatic epoxy resin/CTBN blends containing DDS

\begin{tabular}{lcccc}
\hline S1. no. & CAE $(\mathrm{phr})$ & CTBN $(\mathrm{phr})$ & DDS $(\mathrm{phr})$ & Sample code \\
\hline 1. & 100 & 00 & 40 & $E P_{0100}$ \\
2. & 95 & 05 & 38 & $E P_{0105}$ \\
3. & 90 & 10 & 36 & $E P_{0110}$ \\
4. & 85 & 15 & 34 & $E P_{0115}$ \\
\hline
\end{tabular}

2.3b Thermogravimetric analysis (TGA): The percent weight loss and thermal degradation characteristics of prepared blends were evaluated by thermogravimetric analyser (TGA) recorded on TA Instrument (Model Hi. Res. 2950) TGA unit interfaced with TA instruments Inc. Thermal Analyst 2100 (Du Pont) control unit. The TGA cell was purged with nitrogen at $60 \mathrm{ml} / \mathrm{min}$ during degradation runs. The amount of sample taken was $\sim 5-10 \mathrm{mg}$ in a platinum sample pan. The heating rate in each run was kept at $10^{\circ} \mathrm{C} / \mathrm{min}$ and the temperature range was ambient to $600^{\circ} \mathrm{C}$

2.3c Dynamic mechanical analysis (DMA): The glass transition temperatures of the cured samples were determined by dynamic mechanical analyser (DMA) (TA instruments, Inc, USA; Model DMA 2980). The dynamic mechanical analysis is a well known method for determining viscoelastic properties by applying a controlled sinusoidal strain to a sample and measuring the resulting stress. The measurements were carried out at a heating rate of $10^{\circ} \mathrm{C} / \mathrm{min}$ from ambient to $350^{\circ} \mathrm{C}$ at a fixed frequency level of $1 \mathrm{~Hz}$. The samples for the test were rectangular bars.

2.3d Scanning electron microscopic analysis (SEM): The fractured samples under mechanical analysis were sputter-coated with gold prior to scanning electron microscopic (SEM) examination. Jeol JSM 5800 model was used to view the specimen, several micrographs were taken for each sample.

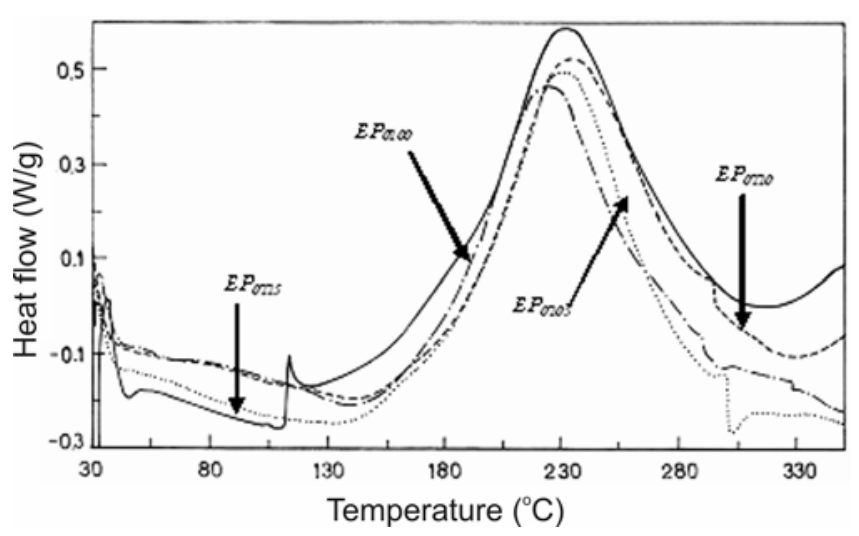

Figure 1. DSC scans of prepared blend samples.

Table 2. Data obtained from DSC traces of prepared blends.

\begin{tabular}{lccccc}
\hline $\begin{array}{l}\text { S1. } \\
\text { no. }\end{array}$ & $\begin{array}{c}\text { Sample } \\
\text { code }\end{array}$ & $T_{\mathrm{o}}\left({ }^{\circ} \mathrm{C}\right)$ & $T_{\mathrm{p}}\left({ }^{\circ} \mathrm{C}\right)$ & $\Delta H(\mathrm{~J} / \mathrm{g})$ & $\begin{array}{c}\text { Cure time } \\
(\mathrm{min})\end{array}$ \\
\hline 1. & $E P_{0100}$ & 178.22 & 232.66 & $288 \cdot 8$ & $17 \cdot 8$ \\
2. & $E P_{0105}$ & 176.55 & 231.29 & 278.8 & $17 \cdot 0$ \\
3. & $E P_{0110}$ & 172.79 & 230.94 & 232.4 & $16 \cdot 2$ \\
4. & $E P_{0115}$ & 181.41 & 223.94 & $187 \cdot 8$ & $18 \cdot 7$ \\
\hline
\end{tabular}


Table 3. Data obtained from TG traces of prepared blends.

\begin{tabular}{lccccccc}
\hline S1. no. & Sample code & $T_{\mathrm{I}}\left({ }^{\circ} \mathrm{C}\right)$ & $T_{\mathrm{P}}\left({ }^{\circ} \mathrm{C}\right)$ & $T_{\mathrm{S}}\left({ }^{\circ} \mathrm{C}\right)$ & $T_{1 / 2}\left({ }^{\circ} \mathrm{C}\right)$ & Mass loss $(\%)$ & Char yield $^{\mathrm{a}}(\%)$ \\
\hline 1. & $E P_{0100}$ & 290 & 370 & 420 & 400 & $80 \cdot 2$ & $19 \cdot 8$ \\
2. & $E P_{0105}$ & 347 & 405 & 516 & 412 & $78 \cdot 3$ & $21 \cdot 7$ \\
3. & $E P_{0110}$ & 350 & 406 & 535 & 418 & $74 \cdot 6$ & $25 \cdot 4$ \\
4. & $E P_{0115}$ & 356 & 417 & 481 & 420 & $86 \cdot 4$ & $13 \cdot 6$ \\
\hline
\end{tabular}

$T_{\mathrm{I}}$, Initial degradation temperature; $T_{\mathrm{P}}$, peak derivative temperature; $T_{\mathrm{S}}$, temperature at which degradation stops; $T_{1 / 2}$, temperature at which material degradates by $50 \%$ and ${ }^{\mathrm{a}}$ char yield at $600^{\circ} \mathrm{C}$.

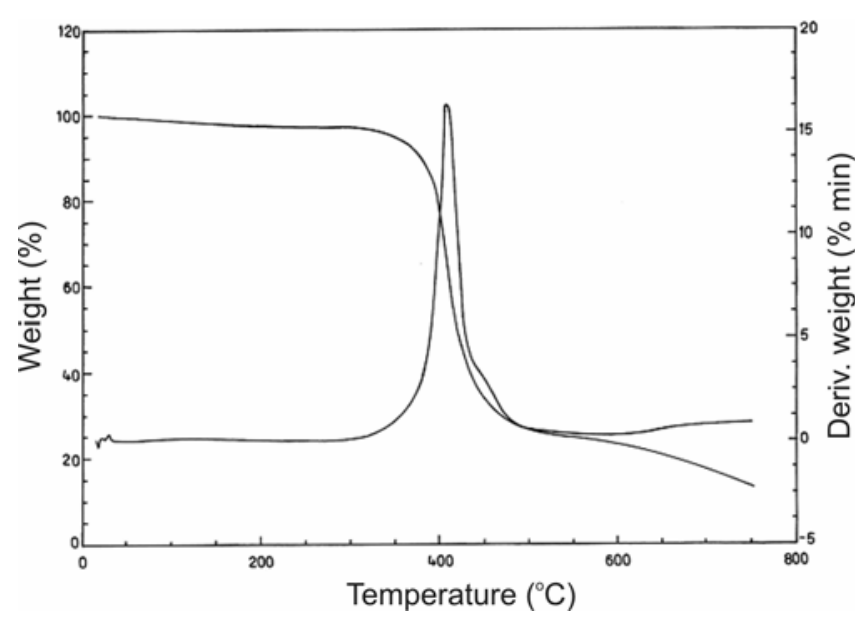

Figure 2. TGA scan of blend sample, $E P_{0110}$.

\section{Results and discussion}

\subsection{Calorimetric analysis}

Figure 1 showed the traces of dynamic test at the DSC, conducted from $25-325^{\circ} \mathrm{C}$ with a heating rate of $10^{\circ} \mathrm{C} /$ min, for all investigated samples. Also, the related data analysed from the DSC traces are given in table 2. From the results, it can be observed that the maximum peak exotherm temperature $\left(T_{\mathrm{P}}\right)$ shifted to a lower temperature side with increasing levels of CTBN (i.e. up to $10 \mathrm{wt} \%$ addition). This behaviour can be interpreted in terms of intermolecular transition state for epoxy-amine, according to this mechanism (Wise et al 2000; Tripathi and Srivastava 2007), strong hydrogen bonding species, such as acids and alcohols, stabilized the transition stage and strongly accelerated the reaction.

The total reaction heat values, $\Delta H$, related to the cure process were determined from the area of the exothermic peak obtained from DSC analysis, taken in the dynamic mode and were found in the range of 180-290 J/g and decreased with increasing content of CTBN in the blend systems (refer table 2). The decrease in the $\Delta H$ values might be attributed to the fact that the increase of CTBN modifier might induce a high reactivity of the end groups with the epoxide ring and resulting shorter curing times and, hence, the faster curing process than the unmodified resin. The decrease of cure time data revealed the same (table 2). A similar conclusion was also given by Wise et al (2000) in their work based on the modification of DGEBA epoxy resin with CTBN or amine-terminated butadiene-acrylonitrile copolymer (ATBN) and cured with diamino diphenyl methane (DDM) and aniline. This may also be attributed to the formation of adduct between the CAE and CTBN resulting in a concomitant decrease in the net volume fraction of CAE with increasing CTBN which ultimately caused the reduction of $\Delta H$ values for epoxy crosslinking (Tripathi and Srivastava 2007).

\subsection{Thermogravimetric analysis}

The blend systems were evaluated for thermal stability in nitrogen atmosphere by thermogravimetric analysis and the TG traces obtained for the blend sample $E P_{0110}$ is shown in figure 2 . The data on initial degradation temperature $\left(T_{\mathrm{I}}\right)$, peak derivative temperature $\left(T_{\mathrm{P}}\right)$, the final decomposition temperature $\left(T_{\mathrm{S}}\right)$, the temperature at which the material degradated $50 \%\left(T_{1 / 2}\right)$ as well as char yield at $600^{\circ} \mathrm{C}$ (which compared the relative thermal stability of the cured blend samples), derived from these traces are given in table 3. The clear-cut single-step mass-loss in TG trace of unmodified and CTBN-modified systems and the shoulders observed in DTG traces of these blend samples indicated a single-step decomposition behaviour (figure 2).

With the initial addition of $5 \mathrm{wt} \% \mathrm{CTBN}$ in CAE (i.e. sample $E P_{0100}$ ), an abrupt increase in $T_{\mathrm{I}}$ was seen (table 3 ). With further addition of CTBN in CAE, a marginal increase in the value of $T_{\mathrm{I}}$ was observed. The addition of increased rubber content, i.e. up to $15 \mathrm{wt} \%$ in unmodified blends, showed the enhancement in the thermal stability of the blends. The variation in the values of char yield with CTBN addition also indicated the same (refer table 3 ). When compared to unmodified system, CTBNmodified blend systems had higher char residue at $600^{\circ} \mathrm{C}$. The increase in thermal stability of the blend systems with increasing rubber content might be attributed to the fact that the rubber started functioning as a thermal stabilizer with increasing temperature and resulted in an increase in the thermal stability of CAE-CTBN blends. However, since the butadiene component of the elastomer contained unsaturation, it would appear to be a site for premature thermal and/or oxidative stability (Riew et al 1976; Pearson and Yee 1986). 
Table 4. Data obtained from DMA traces of prepared blends.

\begin{tabular}{|c|c|c|c|c|c|}
\hline \multirow[b]{2}{*}{ S1. no. } & \multirow[b]{2}{*}{ Sample code } & \multirow[b]{2}{*}{$T_{\mathrm{g}}\left({ }^{\circ} \mathrm{C}\right)$} & \multicolumn{2}{|c|}{ Storage modulus (MPa) } & \multirow[b]{2}{*}{$\rho\left(10^{-3} \mathrm{~mol} / \mathrm{cm}^{3}\right)$} \\
\hline & & & Glassy region $^{\mathrm{a}}$ & Rubbery region ${ }^{\mathrm{b}}$ & \\
\hline 1. & $E P_{0100}$ & 162 & 7248 & $25 \cdot 87$ & $4 \cdot 89$ \\
\hline 2. & $E P_{0105}$ & $122 \cdot 4$ & 7040 & $18 \cdot 35$ & $4 \cdot 27$ \\
\hline 3. & $E P_{0110}$ & $119 \cdot 2$ & 5115 & $12 \cdot 58$ & 2.98 \\
\hline 4. & $E P_{0115}$ & $116 \cdot 1$ & 3175 & $12 \cdot 25$ & 2.95 \\
\hline
\end{tabular}

${ }^{\text {a }}$ Storage modulus at $30^{\circ} \mathrm{C}$; ${ }^{\mathrm{b}}$ storage modulus at $T_{\mathrm{g}}+50^{\circ} \mathrm{C}$.

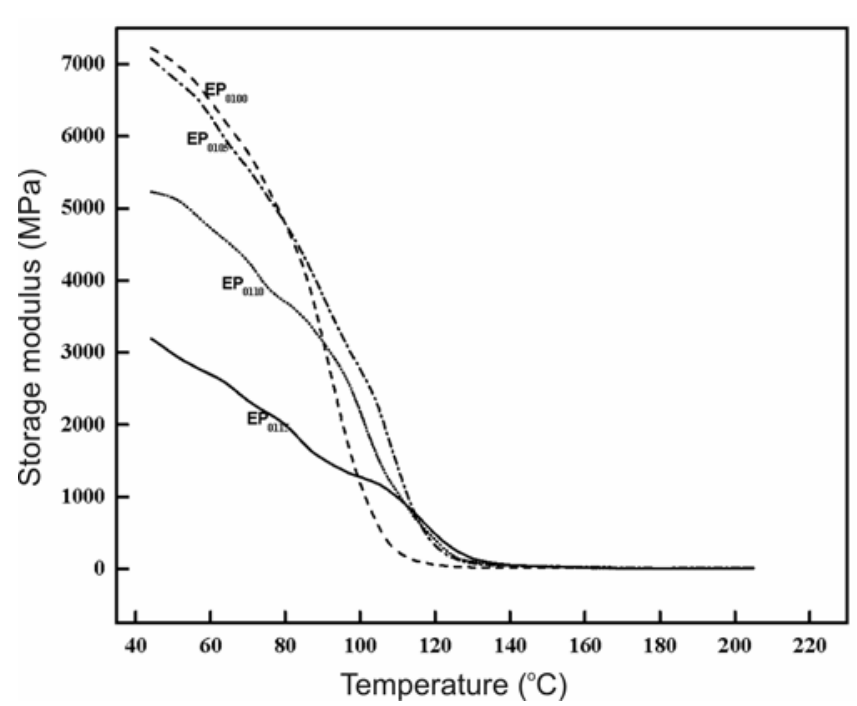

Figure 3. Storage modulus of prepared blend samples.

\subsection{Dynamic mechanical analysis}

The plots consisting of the storage modulus $\left(E^{\prime}\right)$, loss modulus $\left(E^{\prime \prime}\right)$ and loss tangent $(\tan \delta)$ with different proportions of CTBN as a function of temperature have been shown in figures 3-5, respectively and the related data are presented in table 4 . In all the cases, the values of $E^{\prime}$ decreased with increasing temperatures. Also, at any given temperature, the storage modulus decreased with increasing rubber loading which might be due to lowering of the stiffness of matrix (Nigam et al 1998). The values of $E^{\prime \prime}$ and $\tan \delta$ for the prepared samples increased with increasing temperature up to a peak maximum followed by a reversion with further temperature rise. The differences in $E^{\prime \prime}$ and $\tan \delta$ values between the filled and neat epoxy polymer at lower temperature were found to be marginal.

As temperature is increased, it is observed that the damping goes through a maximum in the transition region and then decreases in the rubbery region. The damping is low below $T_{\mathrm{g}}$ as the chain segment in that region is frozen. Below $T_{\mathrm{g}}$, the deformations are thus primarily elastic and the molecular slips resulting in viscous flow is low. Also, above $T_{\mathrm{g}}$, in the rubbery region, the damping is low because the molecular segments are free to move, and

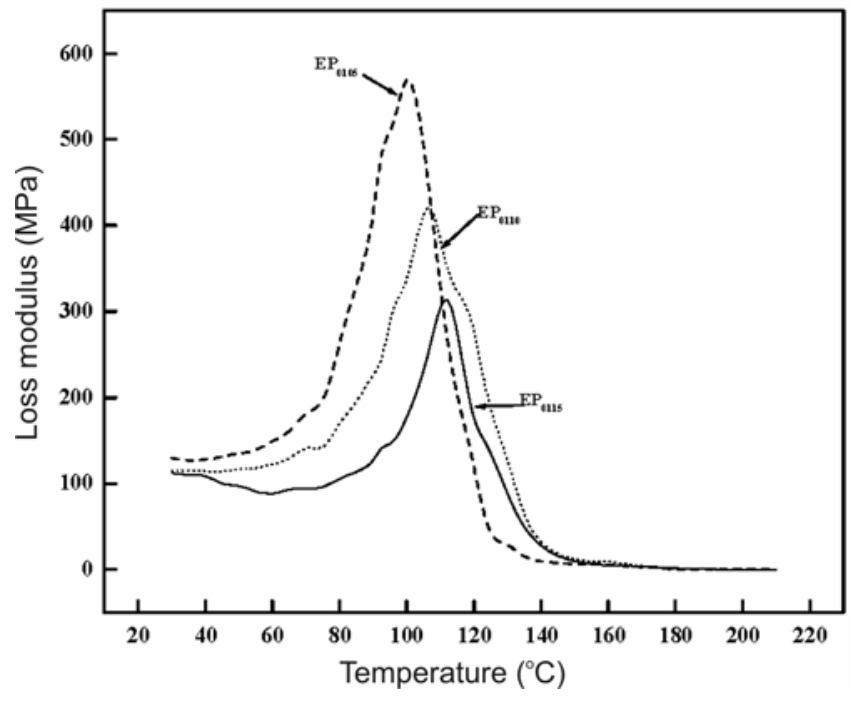

Figure 4. Loss modulus values of prepared blend samples.

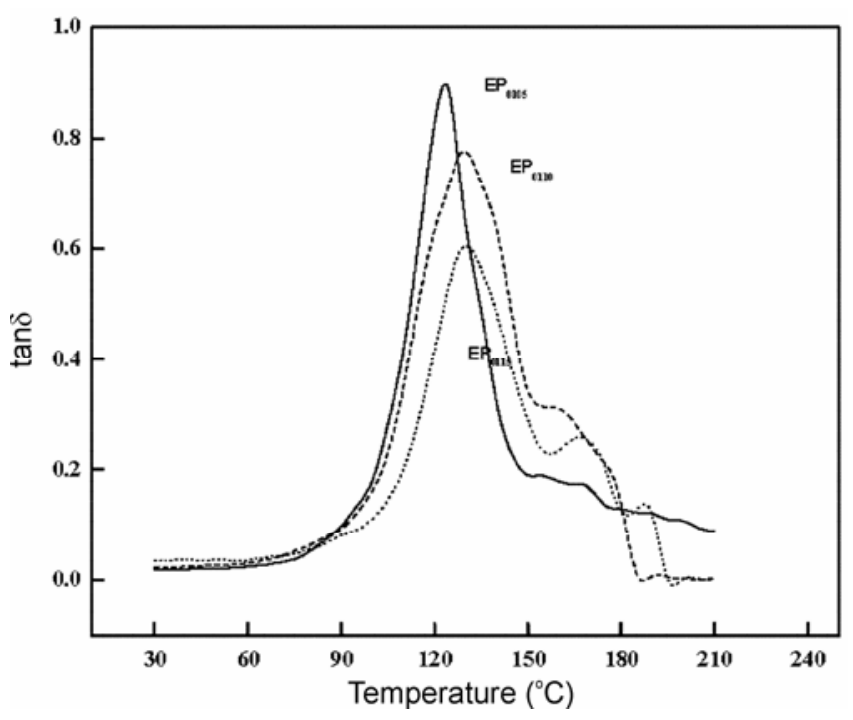

Figure 5. Tan $\delta$ values for prepared blends.

consequently, there is little resistance to flow. In the transition region, on the other hand, the damping is high because of the initiation of micro-processing. The shift of relaxation peak towards low temperature as a result of modification can be attributed to the presence of dissolved rubber. 

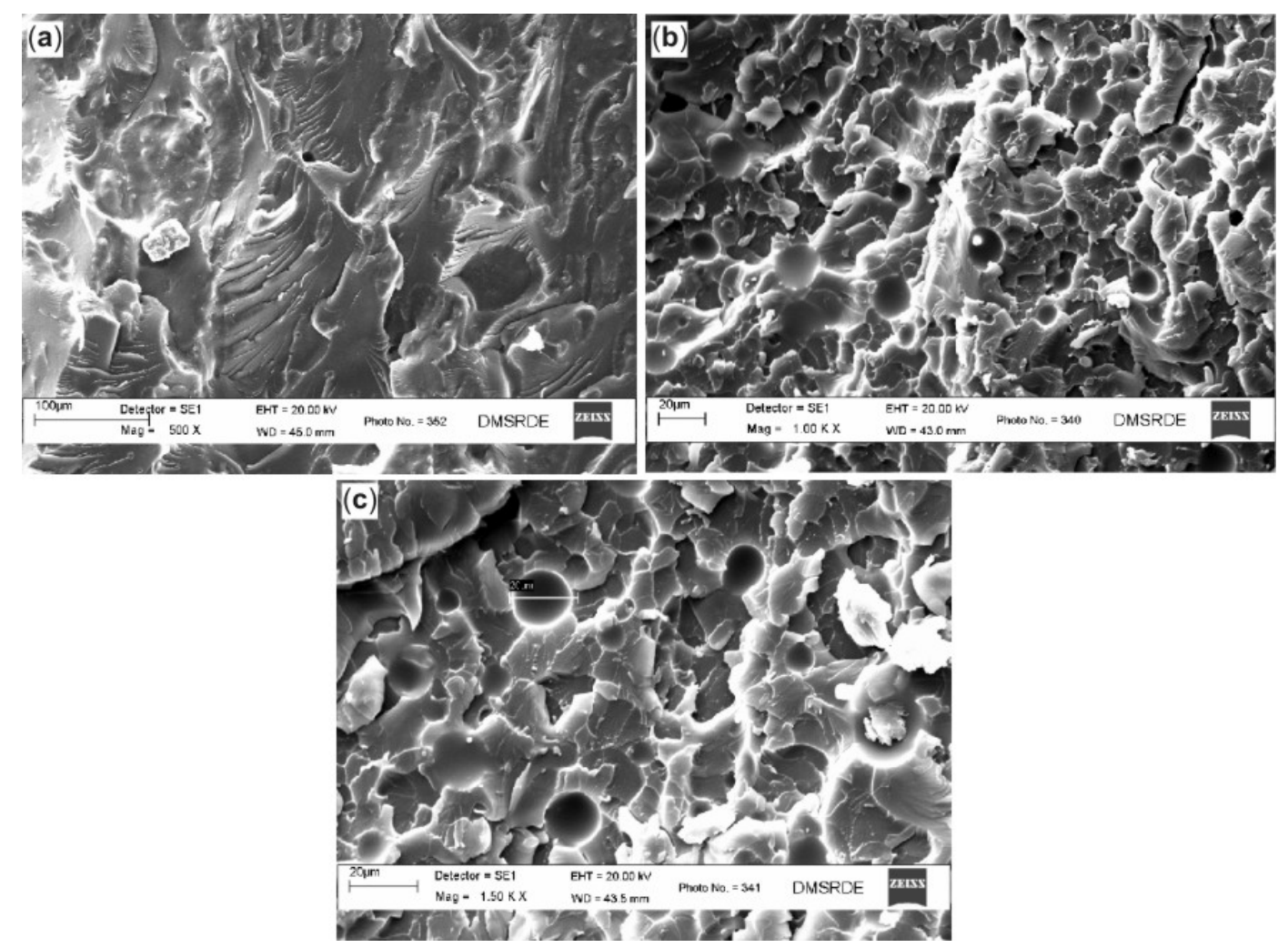

Figure 6. SEM micrographs of prepared blend samples: (a) sample $E P_{0100}$, (b) sample $E P_{0105}$ and (c) sample $E P_{0110}$.

The samples displayed a slightly different dynamic mechanical behaviour by DMA. As seen in table 4 , the neat $\mathrm{CAE}\left(E P_{0100}\right)$ resin retained higher $E^{\prime}$ values at both low and high temperatures than the modified one, which implied that the unmodified had higher crosslinking density $(\rho)$. The values of crosslinking density may be calculated by using (1) as given by Kaji et al (1999)

$$
\rho=\frac{E^{\prime}}{3 R T},
$$

where $E^{\prime}$ is the storage modulus at $T_{\mathrm{g}}+50^{\circ} \mathrm{C}, R$ the gas constant and $T$ the absolute temperature at $T_{\mathrm{g}}+50^{\circ} \mathrm{C}$.

A gradual drop of storage modulus with addition of CTBN revealed increased flexibility of the blend samples. The stiffness of the resultant material was also temperature sensitive (Tripathi et al 2007). The storage modulus dropped with increasing temperature which indicated that all formulations gradually passed from stiff hard solid-to-soft and flexible material which agreed well with previous reasonings (Manzione and Gillham 1981; Verchere et al 1991b; Chikki et al 1997). The damping characteristics also changed with the successive concentration of CTBN in the epoxy matrix as apparent in loss modulus and $\tan \delta$ graphs. Similar results have been reported by Verchere et al (1991a) for epoxy terminated butadiene/acrylonitrile rubber in an aliphatic amine cured DGEBA epoxy.

\subsection{Scanning electron microscopic (SEM) analysis}

At higher rubber content, however, the matrix might be less restrained by the presence of rubber globules with sizes increased by rubber particles coalescence, cavitations and homogeneity of the system (Barton 1974). This could be very well seen in SEM micrographs (figures 6a-c). The pattern of morphology observed for the unmodified formulation (figure 6a) were the characteristics of brittle systems having smooth, glassy fractured surfaces with cracks in different planes. SEM of CTBN-modified systems (i.e. for samples $E P_{0105}$ and $E P_{0110}$ ) showed the presence of precipitated, discrete rubber particles which were dispersed throughout the epoxy matrix, i.e. they revealed the presence of two-phase morphological feature. The soft elastomeric phase was phase separated from the hard epoxy matrix during the early stage of cure. The size of the precipitated rubber particles increased with increasing rubber content in the formulation. The size of the rubber particles, in the epoxy matrix, was larger in sample $E P_{0110}$ than that observed in blend sample $E P_{0105}$. This increase in size of the dispersed rubber phase might be associated with the reagglomeration or coale- 
scence of the dispersed rubber particles (Douglass et al 1980; Chan et al 1984; Dodiuk et al 1987; Sue et al 1996).

\section{Conclusions}

Differential scanning calorimetric studies showed reduction of the extent of isomerization as well as exothermal heat of reaction of epoxy cross linking due to addition of rubber into epoxy matrix. It can also be said that increase of the curing rate was due to a catalytic effect of CTBN carboxyl end groups on the cure process. Thermogravimetric studies showed enhancement of the thermal stability with increasing rubber concentration in the blend. Char yield was increasing which signifies the percent cross linking. Dynamic mechanical analysis signified that rubber filled epoxy composites can behave as a better damping material in dynamic applications compared to brittle epoxy resin. The cross linking density of the prepared blend systems showed similar trend with respect to $T_{\mathrm{g}}$ in particular.

\section{Acknowledgements}

Authors are thankful to the Director, DMSRDE, Kanpur, for technical facilities. Special thanks are due to Sri S B Yadaw and Sri R K Gupta, Composite Division, for solving experimental problems. Thanks are also due to Ms Punam Awasthi for DSC analysis, Mr Amitabh Chakraborty and Mr C B Vishwakerma for doing TGA and DMA. Also, we thankfully acknowledge the contributions rendered by M/s Emerald Performance Materials, LLC, Hong Kong, for providing CTBN and M/s Ciba Specialty Chemicals Pvt. Ltd, Mumbai, for providing cycloaliphatic epoxy resin, respectively well in time.

\section{References}

Bartlet P, Pascault J P and Sautereau H 1985 J. Appl. Polym. Sci. 302955

Barton J M 1974 J. Macromol. Sci. Chem. A8 25

Batzer H 1964 Chem. Ind. (London) 1179

Bittmann E and Ehrenstein G W 1998 Angew. Macromol. Chem. 25893

Buchwalter S L and Kosbar L L 1996 J. Polym. Sci. Part A: Polym. Chem. 34249
Chan L C, Gillham J K, Kinloch A J and Shaw S J 1984 in Rubber-modified epoxies: morphology, transitions and mechanical properties (eds) C K Riew and JK Gillham (Washington, DC: American Chemical Society) Vol ACS 208, p. 274

Chen D, Pascault J P and Sautereau H 1993 Polym. Int. 32361

Chen T K and Tan Y H 1991 Polym. Engg. Sci. 31577

Chikki N, Fellahi S and Bakar M 1997 Eur. Polym. J. 383251

Dodiuk H, Kenig S and Liran I 1987 J. Adhesion 22248

Douglass S K, Beaumont P W R and Ashby M F 1980 J. Mater. Sci. 151109

Frigione M E, Mascia L and Acierno D 1995 Eur. Polym. J. 31 1021

Kaji M, Nakahara K and Endo T 1999 J. Appl. Polym. Sci. 74 690

Kim J K and Robertson R E 1992 J. Mater. Sci. 27161

Lee H and Neville K 1982 Handbook of epoxy resins (New York: McGraw-Hill)

Lee S M 1988 in Epoxy resins (ed.) C A May (New York: Marcel Dekker) 2nd edn, pp 860-868

Manzione L J and Gillham J K 1981 J. Appl. Polym. Sci. 26889

Nigam V, Setua D K and Mathur G N 1998 J. Appl. Polym. Sci. 70537

Pearson R A and Yee A F 1986 J. Mater. Sci. 212475

Pearson R A and Yee A F 1989 J. Mater. Sci. 242571

Riew C K and Gillham J K (eds) 1984 Rubber modified thermoset resins (Washington, DC: American Chemical Society)

Riew C K, Rowe E H and Siebert A R 1976 Adv. Chem. Series 154326

Sadhir R K and Luk M R 1992 Expanding monomers: Synthesis, characterization and applications (Boca Raton: CRC FL)

Soldates A C and Burhans A S 1971 Adv. Chem. Ser. 99531

Soucek M D 2003 Chem. J. J. Coat. Technol. 7549

Sue H J, Garciameitin E I and Pickelman D M 1996 in Polymer toughening (ed.) C B Arands (New York: Marcel Dekker) pp. $131-173$

Sultan J N and Mc-Garry F J 1973 Polym. Engg. Sci. 1329

Sultan J N, Liable R C and Mc-Garry F J 1971 Polym. Symp. 16 127

Tokixava M, Ozawa N and Wakabayashi N 1993 J. Appl. Polym. Sci. 50875

Tripathi G and Srivastava D 2007 Mater. Sci. Engg. A443 262

Verchere D, Pascault J P, Sautereau H, Moschair S M, Riciardi C C and Williams R J 1991 J. Appl. Polym. Sci. 42701

Verchere D, Sautereau H, Pascault J P and Mosechain S M 1991 J. Appl. Polym. Sci. 42717

Visconti S and Marchessault R H 1974 Macromolecules 7913

Wise C W, Cook W D and Goodwin A A 2000 Polymer 41 4625

Yee A F and Pearson R A 1989 J. Mater. Sci. 212462 